\title{
CS Term Type
}

National Cancer Institute

\section{Source}

National Cancer Institute. CS Term Type. NCI Thesaurus. Code C53664.

The $\mathrm{NCl}$ term type designation for a US State Department standard country code. 